\title{
PENGARUH KUALITAS PELAYANAN DAN FASILITAS TERHADAP KEPUASAN PENGGUNA PERPUSTAKAAN (DI POLITEKNIK NEGERI BATAM)
}

\author{
Gunartik $^{1}$, Nora Pitri Nainggolan ${ }^{2}$ \\ ${ }^{1}$ Mahasiswa Program Studi Manjemen, Universitas Putera Batam \\ ${ }^{2}$ Dosen Program Studi Manajemen, Universitas Putera Batam
}

\section{email: unaazza81@gmail.com}

\begin{abstract}
The library is a place that becomes a service provider that contains information. Independent variables in this study are service quality and facilities, the dependent variable is library user satisfaction. This study aims to study the quality of services and facilities for library user satisfaction. by using primary data and secondary data, data collection techniques by distributing questionnaires. The population in this study were students using the Business Administration (AB) library in 2018 in the last three months, namely July, August, September as many as 3208 people. The sample in this study amounted to 100 taken using probability sampling techniques with random sampling method. The results of the study stated that valid and reliable, normal, did not occur Multicollinearity and Heteroscedasticity. The results of the F Test show that the quality of service and facilities have a positive and significant effect on the satisfaction of library users. the results of the T Test show that the value of service quality has a positive and significant effect on user satisfaction. while facilities have a positive and significant effect on user satisfaction.
\end{abstract}

Keywords: Service Quality; Facilities; User Satisfaction Training.

\section{PENDAHULUAN}

Pada umumnya perpustakaan merupakan suatu tempat yang menjadi penyedia layanan yang berisi informasi atau koleksi, baik itu secara ilmiah maupun non ilmiah.Dilihat dari keberadaan perpustakaan yang mempunyai Fasilitas dan Pelayanan yang mendukung disetiap Perguruan Tinggi, ini sudah mencerminkan keberhasilan perguruan tinggi tersebut. Dengan adanya perpustakaan tersebut dapat membantu penyebaran informasi dan juga membantu proses bejalar mandiri. Perpustakaaan tersebut juga dapat membantu seseorang dalam menyelesaikan tugas kampus, penelitian, serta hal hal lain yang dapat ditemukan di perpustakaan. Dengan adanya kualitas pelayanan yang baik maka pengguna perpuastakaan akan lebih nyaman dan mereka akan lebih senang membaca diperpustakaantersebut.

Kualitas pelayanan merupakan suatu perbandingan yang menjadi ukurang penting dari suatu pelayanan yang diberikan ataupun yang diinginkan pelanggan. Kesimpulannya terletak dari kemampuan dari suatu instansi dalam mewujudkan harapan dari pelanggan. (Tjiptono, 2008 : 85). Fasilitas yang lengkap merupakan suatu daya tarik tersendiri bagi penggunanya.Perpustakaan daya tarik utanya terletak pada fasilitas yang ada didalamnya, jika fasilitasnya kurang lengkap maka perpustakaannya pun kurang menarik dan cenderung tidak bnyak pengunjung yang dating. Pengguna akan senantiasa beralih keperpustakaan yang lain yang justru lebih fasilitasnya dari jurnal (Sari, Purnama dan Jamil, 2016 : 22). Jika dalam suatu pelayanan dan fasilitas yang tidak baik pastinya akan memberikan kesan yang tidak baik pula kepada pembaca. 
Politeknik Negeri Batam (Polibatam) ialah satu satunya Perguruan Tinggi Negeri (PTN) yang berada di pusat Kota Batam.Sering kali dalam pelaksanaannya terdapat kesulitan yang selalu dialami bagi kebanyakan mahasiswa pengguna Perpustakaan Politeknik Negeri Batam. Adapun yang menjadikeluhan- keluhan tersebut mengenai ketersediaan buku-buku yang ada masih dirasakan sangat kurang, oleh karena itu menimbulkan rasa kekecewaan bagi pengguna perpustakaan dalam mencari buku yang akan dibacanya. Selanjutnya untuk mengakses layanan perpustakaan tersebut dirasakan kurang efektif, karena computer yang disediakan untuk mencari buku hanya satu (1) sehingga apabila ramai pengunjung perpustakaan yang datang untuk mencari buku akan menimbulkam antrian yang panjang.

Keluhan fasilitas yang perlu di tata dengan baik bisa di lihat dari ruangan yang sempit, koleksi buku yang kurang lengkap, kurangnya informasi dan petunjuk tata cara dalam pemanfaatan layanan, pencahayaan yang kurang terang, tidak adanya rak sepatu didalam ruangan baca sehingga sepatu/alas kaki berserakan. Serta jumlah meja yang disediakan kurang memadai.

Berikut ini adalah data pengunjung perpustakaan di Politeknik Negeri Batam adalah sebagai berikut:

Tabel 1.Data Pengunjung 3 bulan terakhir (Juli,Agustus dan September)

\begin{tabular}{|c|c|c|c|c|}
\hline \multirow{2}{*}{ Pengguna } & \multicolumn{3}{|c|}{ Bulan } & \multirow[b]{2}{*}{ jumlah } \\
\hline & 31Juli 2018 & 31 Agustus 2018 & 30 Sept 2018 & \\
\hline Akutansi (AK) & 226 & 1611 & 963 & 2800 \\
\hline $\begin{array}{l}\text { Akutansi } \quad \text { Manajerial } \\
\text { (AM) }\end{array}$ & 88 & 1466 & 995 & 2549 \\
\hline Administrasi Bisnis (AB) & 190 & 2129 & 889 & 3208 \\
\hline Informatika (IF) & 395 & 1575 & 1067 & 3037 \\
\hline Multimedia jaringan(MJ) & 385 & 951 & 615 & 1951 \\
\hline $\begin{array}{l}\text { Elektronik manufaktur } \\
\text { (EM) }\end{array}$ & 9 & 353 & 95 & 457 \\
\hline Mekatronika(MK) & 281 & 1438 & 507 & 2226 \\
\hline Elektronika (EL) & 75 & 702 & 353 & 1130 \\
\hline Umum & 128 & 119 & 87 & 334 \\
\hline
\end{tabular}

Sumber :Perpustakaan Politeknik Negeri Batam, 2018

Berdasarkan data pengunjung mahasiswa 3 bulan terakhir terhitung pada bulan (july, Agustus, dan September) perjurusan. Pada tabel diatas dapat diketahui pengunjung perpustakaan mengalami fase naik turun untuk datang keperpustakaan. Menurut peneliti fase naik turun pengguna perpustakaan tersebut dikarenakan adanya kendala dalam pelayanan petugas, misalnya petugas yang kurang ramah, kurang cekatan jika pengguna mengalami permasalahan dalam mencari buku. Berdasarkan uraian aspek- aspek di atas yang telah dijelaskan dalam latarbelakang maka penulis menarik kesimpulan untuk melakukan penelitian dengan mengambil judul "Pengaruh Kualitas Pelayanan dan Fasilitas terhadap Kepuasan Pengguna Perpustakaan (Di Politeknik Negeri Batam)"

Adapun rumusan masalah dalam penelitian ini adalah:

1. Apakah kualitas pelayanan berpengaruh secara parsial terhadap kepuasan pengguna perpustakaan di Politeknik Negeri Batam?

2. Apakah fasilitas berpengaruh secara parsial terhadap kepuasan pengguna perpustakaan di Politeknik Negeri Batam? 
3. Apakah kualitas pelayanan dan fasilitas berpengaruh secara simultan terhadap kepuasan pengguna perpustakaan di Politeknik Negeri Batam?

\section{TINJAUAN PUSTAKA}

\section{Kualitas Pelayanan}

Menurut (Tjiptono, 2012 :78) kualitas merupakan ciri-ciri , bahan atau perlengkapan obyektif yang mampu di kuantitatifkan dan dapat diukur. Menurut (Majid, 2009 : 36).Pelayanan adalah kata kerja yang sifatnya pasif, dinamis bukan statis, proaktif bukan reaktif, dan peduli terhadap orang lain dalam arti lain suka menolong orang lain bukan diam saja atau acuh tak acuh. Berdasarkan defenisi diatas dapat ditarik kesimpulan kualitas pelayanan berfokus terhadap pemenuhan keinginan dari pengguna perpustakaan sendiri jika belum memberikan kepuasan terhadap pengguna, maka kualitas pelayanan yang diberikan masih sangat jauh dari kata berhasil. Harapan dan keinginan pengguna hendaknya harus sejalan dengan karyawan yang memberikan pelayanan tersebut. Jika sudah sejalan maka karyawan atau pelaku pelayanan akan sejalan memberikan kualitas dan pemenuhan harapan dari pengguna pelayanan tersebut. Maka pasti akan sesuai standart karyawan dan harapan dari pengguna pelayanan itu sendri.

\section{Fasilitas}

Menurut (Hadiguna, 2008: 10) Fasilitas merupakan tepat yang berguna memfasilitasi kelancaran yang dilkukan perpustakaan. Semangkin bagus fasilitas yang disampaikan kepada pengguna, jadi akan semakin lebih baik kepuasan konsumen. Menurut jurnal (Nawawi \& Puspitowati, 2015 : 320-334). fasilitas merupakan sarana penunjang termasuk semua barang serta jenis perlengkapan, peralatan maupun pelayanan yang memiliki fungsi utama sebagai pelengkap suatu pekerjaan.serta menjadi atribut utama untuk melaksanakan. Menurut jurnal (Nawawi \& Puspitowati, 2015 : 320-334) fasilitas merupakan sarana penunjang termasuk segala jenis peralatan, perlengkapan kerja .

\section{Kepuasan Pengguna}

Menurut (Rangkuti, 2017 :79) Kepuasan ialah respons konsumen terhadap ujian dan ketidakcocokan antara perbandingan apa yang diharapan sebelumnya dan kinerja aktual produk setelah pemakaian. Menurut (Sangadji, 2013 : 181) Kepuasan ialah pandangan dari pengguna untuk mengapresiasikan harapan yang ia inginkan dengan apa yang diberikan. Pencapaian kepuasan merupakan suatu proses yang sederhana, maupun kompleks yang rumit. Untuk mengetahui tingkat kepuasan pengguna lebih baik harus mengetahui sebab-sebab kepuasan.Kepuasan atau ketidakpuasan ialah ungakapan perasaan senang ataupun bias dikatakan kekekecewaan seseorang yang biasanya muncul karena adanya perbandingan diantara apa yang dirasakan dari kinerja yang langsung maupun yang tidak langsung dari suatu harapan yang dibutuhkannya. Menurut jurnal (Ningrum Roh, 2014) kepuasan pengguna merupakan timbal balik dari orang yang menjadi pengguna perilaku yang langsung ditunjukkan oleh pelanggan dan langsung bias dirasakan puas atau tidaknya suatu kinerja tersebut. Pengukuran dari kepuasan pelanggan itu biasanya menggunakan system keluhan dan saran yang disediakan pihak penyedia layanan atau bias juga menggunakan survey kepuasan pelanggan menggunakan Ghost Shopping, lost customer Analisis.

\section{Penelitian Terdahulu}

Pentingnya Penelitian terdahulu sebagai dasar dalam rangka menyusun skripsi ini. Penelitian dari (Adhitomo Wirawan \& Risfandi, 2018) dengan judul Pengaruh fasilitas perpustakaan, kinerja pustakawan dan kualitas informasi terhadap kepuasan mahasiswa dalam menggunakan perpustakaan Politeknik Negeri Batam dengan hasil penelitian ini menemukan bahwa fasilitas,kinerja, dan faktor kualitas berpengaruh signifikan terhadap kepuasan pengguna. 


\section{METODE}

Penelitian ini berpedoman dengan penelitian yang bersifat kuantitatif dengan mencari hubungan kausal Menurut (Sanusi, 2011 :14-15) Desain suatu penelitian kausalitas ialah desain dari penelitian yang susunannya menjadi tolak ukur suatu penelitian yang menghubungkan sebab akibat antar suatu variabel. Teknik analisis data penelitian ini menggunakan analisis deskriptif, uji validitas, uji reliabilitas, uji normalitas, uji multikolinearitas, uji heteroskedastisitas, uji analisis linear berganda, uji simultan (t), uji parsial (f), dan uji koefisien determinasi $\left(\mathrm{R}^{2}\right)$.

\section{Lokasi Penelitian}

Lokasi dalam penelitian ini yaitu di Perpustakaan Politeknik Negeri Batam yang lokasinya di Jl. Ahmad Yani Batam Kota. Kota Batam kepulauan Riau. Indonesia.

\section{HASIL DAN PEMBAHASAN}

Penelitian ini menggunakan software program SPSS versi 2.0.

\section{Hasil Uji Validitas}

Tabel 2.Output Uji Validitas

\begin{tabular}{lllll}
\hline Variabel & $\begin{array}{l}\text { Item } \\
\text { Pernyataan }\end{array}$ & $\begin{array}{l}\text { Pearson } \\
\text { Correlations } \\
\left(\mathrm{R}_{\text {hitung }}\right.\end{array}$ & $\begin{array}{l}\mathrm{R}_{\text {tabel }}(\mathrm{n}=100 \mathrm{a}) \\
=0,1)\end{array}$ & Kesimpulan \\
Kualitas Pelayanan & $\mathrm{X} 1-1$ & 0,647 & 0.1638 & Valid \\
(X1) & $\mathrm{X} 1-2$ & 0,843 & 0.1638 & Valid \\
& $\mathrm{X} 1-4$ & 0,726 & 0.1638 & Valid \\
& $\mathrm{X} 1-5$ & 0,785 & 0.1638 & Valid \\
Fasilitas & X2-1 & 0,786 & 0.1638 & Valid \\
(X2) & X2-2 & 0,825 & 0.1638 & Valid \\
& X2-3 & 0,808 & 0.1638 & Valid \\
& X2-4 & 0,902 & 0.1638 & Valid \\
Kepuasan Pengguna & Y1-1 & 0,606 & 0.1638 & Valid \\
(Y) & Y1-2 & 0,736 & 0.1638 & Valid \\
& Y1-3 & 0,604 & 0.1638 & Valid \\
& Y1-5 & 0,635 & 0.1638 & Valid \\
& Y1-6 & 0,519 & 0.1638 & Valid \\
\hline
\end{tabular}

Sumber: Data Primer yang di olah SPSS 20, 2018

Berdasarkan penjelasan tersebut dapat diketahui bahwa korelasi dari variabel kualitas pelayanan (X1),fasilitas (X2),dan kepuasan pengguna(Y) menunjukkan bahwa $r$ hitung $>r$ tabel dalam pearson Correlationnya atau Hasil $r$ tabel di peroleh dari Tabel $r$ dengan jumlah $n=100$ pada taraf signifikan 0,01 (uji dua sisi) sehingga di peroleh angka 0,1638 dan hal ini dinyatakan valid.

\section{Hasil Uji Reliabilitas}

Tabel 3. Output Uji Reliabilitas

\begin{tabular}{cll}
\hline Variabel & Cronbach's Alpha & Kesimpulan \\
\hline Kualitas Pelayanan & 0,796 & Reliabel \\
Fasilitas & 0,872 & Reliabel \\
Kepuasan Pengguna & 0,684 & Reliabel \\
\hline
\end{tabular}

Sumber: Data Primer yang di olah SPSS 20, 2018

Reliabilitas dari Uji menunjukkan bahwa variabel nilai kualitas pelayanan mempunyai koefisien Cronbach's Alpha sebesar 0,796, variabel fasilitas mempunyai koefisien Cronbach's Alpha sebesar 0,872, dan variabel kepuasan pengguna mempunyai koefisien sebesar 0,684 yang 
menunjukkan hasil uji reliabilitas di atas 0,60. Maka dari tabel tersebut dapat dikatakan semua konsep pengukur masing-masing variabel dari kuesioner adalah reliabel.

\section{Hasil Uji Normalitas}

Tabel 4.Hasil Uji Normalitas

One-Sample Kolmogorov-Smirnov Test

\begin{tabular}{lll}
\hline & & $\begin{array}{l}\text { Unstandardized } \\
\text { Residual }\end{array}$ \\
\hline & & \\
$\mathrm{N}$ & & 100 \\
Normal Parameters ${ }^{\mathrm{a}, \mathrm{b}}$ & Mean & $0 \mathrm{E}-7$ \\
& Std. Deviation & 2.49238305 \\
& Absolute & .060 \\
Most Extreme Differences & Positive & .034 \\
& Negative & -.060 \\
Kolmogorov-Smirnov Z & & .595 \\
Asymp. Sig. (2-tailed) & & .871 \\
\hline
\end{tabular}

a. Test distribution is Normal.

b. Calculated from data.

Sumber: Data Primer yang di olah SPSS 20, 2018

Berdasarkan uji Kolmogrov-Smirnov yang telah terlihat, maka bisa di ambil kesimpulan bahwa data memiliki distribusi yang normal yang disebabkan nilai Asymp.Sig. (2-tailed) sebesar 0,871 yang jelas lebih besar jikalau dibandingkan 0,05. Jadi kesimpulannya data telah lulus dari uji normalitas One-Sample Klomogorov-Smirnov Test.

\section{Hasil Uji Heteroskedastisitas}

Tabel 5 Hasil uji Heteroskedastisitas Park Gleyser

\begin{tabular}{|c|c|c|c|c|c|c|}
\hline \multirow{2}{*}{ Model } & & \multicolumn{2}{|c|}{ Unstandardized Coefficients } & $\begin{array}{l}\text { Standardized } \\
\text { Coefficients }\end{array}$ & \multirow[t]{2}{*}{$\mathrm{t}$} & \multirow[t]{2}{*}{ Sig. } \\
\hline & & B & Std. Error & Beta & & \\
\hline \multirow{3}{*}{1} & (Constant) & $-8.660 \mathrm{E}-016$ & 2.077 & & .000 & 1.000 \\
\hline & Kualitas Pelayanan & .000 & .086 & .000 & .000 & 1.000 \\
\hline & Fasilitas & .000 & .074 & .000 & .000 & 1.000 \\
\hline
\end{tabular}

Sumber: Data Primer yang di olah SPSS 20, 2018

Penelitian jika tidak terdapat gejala heteroskedastisitas jika suatu nilai probabilitas atau signifikansinya $>0,05$. Berdasarkan tabel yang telah tersedia dapat diketahui untuk nilai probabilitas atau signifikansi untuk masing-masing variable sebesar 1,000. Hasil output dijelaskan bahwa korelasi antara x1_Kualitas di dalam Unstandardized Residual berada pada signifikansi 1,000 sedangkan untuk korelasi x2 _Fasilitas didalam Unstandardized Residual berada pada signifikansi 1,000. Dari penelitian ini dua variabel memiliki nilai lebih besar dari 0,05 , kesimpulannya adalah dalam bentuk regresi tidak terdapat gejala heteroskedastisitas. Untuk selanjutnya uji heteroskedastisitas ini dapat dilihat pada Uji Scatter Plot dibawah ini: 


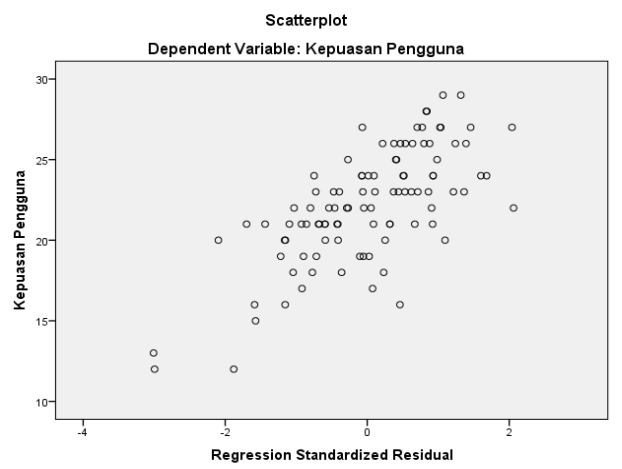

Gambar 1. Scatter plot

\section{Sumber : Hasil Pengolahan Data Primer, 2018}

Gambar 1 di scatter plot dapat diliat titik-titik menyebar dengan pola yang tidak jelas di atas dan berada di sekitar angka 0 di sumbu Y jadi bias dikatakan bahwa pada model regresi tidak terjadi masalah heteroskedastisitas.

\section{Hasil Uji Multikolinearitas}

Tabel 6. Hasil Uji Multikolinearitas

\begin{tabular}{|c|c|c|c|c|c|c|c|c|}
\hline \multirow[b]{2}{*}{ Mode } & & \multicolumn{2}{|c|}{$\begin{array}{l}\text { Unstandardized } \\
\text { Coefficients }\end{array}$} & \multirow{2}{*}{$\begin{array}{l}\text { Standardized } \\
\text { Coefficients } \\
\text { Beta }\end{array}$} & \multirow[t]{2}{*}{$\mathrm{t}$} & \multirow[t]{2}{*}{ Sig. } & \multicolumn{2}{|c|}{$\begin{array}{l}\text { Collinearity } \\
\text { Statistics }\end{array}$} \\
\hline & & B & Std. & & & & Tolerance & VIF \\
\hline \multirow{3}{*}{1} & (Constant) & 4.425 & 2.07 & & 2.130 & .036 & & \\
\hline & $\begin{array}{l}\text { Kualitas } \\
\text { Pelayanan }\end{array}$ & .430 & .086 & .359 & 4.995 & .000 & 1.000 & 1.000 \\
\hline & Fasilitas & .632 & .074 & .615 & 8.561 & .000 & 1.000 & 1.000 \\
\hline
\end{tabular}

Sumber: Data Primer yang di olah SPSS 20, 2018

Tabel yang terlihat diatas diketahui bahwa Tolerance memiliki nilai 0,997 yaitu >0,1 dan VIF memiliki suatu nilai sebesar $1.003<10$. Oleh karena kesimpulannya kalau dalam model regresi ini tidak terjadi masalah multikolinearitas.

\section{Hasil Uji Regresi Linear Berganda}

Tabel 7. Output Uji Regresi Linier Berganda

\begin{tabular}{|c|c|c|c|c|c|c|}
\hline \multirow[b]{2}{*}{ Model } & & \multicolumn{2}{|c|}{$\begin{array}{l}\text { Unstandardized } \\
\text { Coefficients }\end{array}$} & \multirow{2}{*}{$\begin{array}{l}\text { Standardized } \\
\text { Coefficients } \\
\text { Beta }\end{array}$} & \multirow[t]{2}{*}{$\mathrm{t}$} & \multirow[t]{2}{*}{ Sig. } \\
\hline & & B & Std. Error & & & \\
\hline \multirow{3}{*}{1} & (Constant) & 4.425 & 2.077 & & 2.130 & .036 \\
\hline & $\begin{array}{l}\text { Kualitas } \\
\text { Pelayanan }\end{array}$ & 430 & .086 & .359 & 4.995 & .000 \\
\hline & Fasilitas & .632 & .074 & .615 & 8.561 & .000 \\
\hline
\end{tabular}

Sumber: Data Primer yang di olah SPSS 20, 2018 
Persamaan dalam suatu regresi dinyatakan dengan menggunakan rumus regresi linear berganda sebagai berikut:

$\mathrm{Y}=4.425+0,430 \mathrm{X} 1+0,632 \mathrm{X} 2$

Keterangan:

Y : Kepuasan Pengguna

$\mathrm{X} 1 \quad$ : Kualitas Pelayanan

$\mathrm{X} 2 \quad$ : Fasilitas

Dari persamaan di atas dapat dijelaskan bahwa:

1. Konstanta memiliki nilai sebesar 4.425 ini menunjukan jika X1(Kualitas Pelayanan) dan X2(Fasilitas) nilai nol, maka Y, (Kepuasan Pengguna) memiliki nilai 4.425.

2. Variabel dependenX1(Kualitas Pelayanan) memiliki nilai koefisien regresi sebesar 0,430, ini berarti jika suatu variabel independen lain nilainya tidak terjadi pergeseran, maka dapat disimpulkan setiap kenaikan dari 1 point atau $1 \%$ suatu variabel kualitas pelayanan dapat meningkatkan nilai kepuasan pengguna sebesar 0,430 atau 43\%. . Koefisien variabel X1(Kualitas Pelayanan) bernilai positif artinya terdapat hubungan positif antara X1(Kualitas Pelayanan) dengan Y(Kepuasan Pengguna), artinya semangkin meningkat nilai X1(Kualitas Pelayanan) maka akan meningkatkan Y,(Kepuasan pengguna).

3. Variabel X2 (Fasilitas) memiliki nilai koefisien regresi sebesar 0,632, ini berarti jika variabel independen lain nilainya tetap atau tidak berubah, maka setiap kenaikan 1 poin atau $1 \%$ variabel kualitas pelayanan terjadi peningkatkan dalam suatu nilai kepuasan konsumen sebesar 0,632 atau $63,2 \%$. Koefisien variabel X2 (Fasilitas) bernilai positif artinya terdapat pengaruh yang positif antara X2 (Fasilitas) dengan Y (Kepuasan Pengguna), artinya semakin meningkat nilai X2 (Fasilitas) maka akan meningkatkan Y(Kepuasan Pengguna).

\section{Hasil Uji Koefisien Determinasi $\left(\mathbf{R}^{2}\right)$}

Tabel 8. Hasil Uji Determinasi $\left(\mathrm{R}^{2}\right)$

\begin{tabular}{lllll}
\hline Model & $\mathrm{R}$ & R Square & Adjusted R Square & $\begin{array}{l}\text { Std. Error of the } \\
\text { Estimate }\end{array}$ \\
\hline 1 & $.707^{\mathrm{a}}$ & .500 & .489 & 2.518 \\
\hline
\end{tabular}

Sumber: Data Primer yang di olah SPSS 20, 2018

Pada tabel 8 diatas diketahui output uji deterinasi memperlihatkan bahwa untuk nilai $R$ Square sebesar 0,500 menunjukkan besarnya peran atau kontribusi variabel kualitas pelayanan dan fasilitas menjelaskan 50\% sedangkan sisanya dari variabel lain sebesar 50\% dan tidak dimasukkan dalam penelitian ini.

\section{Hasil Uji Parsial (T)}

Tabel 9. Hasil Uji T

\begin{tabular}{|c|c|c|c|c|c|c|}
\hline \multirow{2}{*}{ Model } & & \multicolumn{2}{|c|}{ Unstandardized Coefficients } & \multirow{2}{*}{$\begin{array}{l}\text { Standardized } \\
\text { Coefficients } \\
\text { Beta } \\
\end{array}$} & \multirow[t]{2}{*}{$\mathrm{t}$} & \multirow[t]{2}{*}{ Sig. } \\
\hline & & B & Std. Error & & & \\
\hline & (Constant) & 4.425 & 2.077 & & 2.130 & .036 \\
\hline 1 & $\begin{array}{l}\text { Kualitas Pelayanan } \\
\text { Fasilitas }\end{array}$ & $\begin{array}{l}.430 \\
.632\end{array}$ & $\begin{array}{l}.086 \\
.074\end{array}$ & $\begin{array}{l}.359 \\
.615\end{array}$ & $\begin{array}{l}4.995 \\
8.561\end{array}$ & $\begin{array}{l}.000 \\
.000\end{array}$ \\
\hline
\end{tabular}

Sumber: Data Primer yang di olah SPSS 20, 2018 
Tabel 9 menunjukkan bahwa pengujian regresi variable kualitas pelayanan memiliki taraf signifikansi sebesar 0,000 dan memperlihatkan bahwa taraf signifikansinya lebih kecil dari 0,00 dan disimpulkan bahwa variabel kualitas pelayanan memberikan pengaruh yang signifikan terhadap variabel kepuasan pengguna. Variabel fasilitas untuk tingkat taraf signifikansi 0,000 memperlihatkan signifikansi yang bertaraf lebih kecil dari 0,05 dan disimpulkan variabel fasilitas dapat memberikan suatu pengaruh yang signifikan terhadap suatu variabel kepuasan pengguna

\section{Hasil Uji F}

Tabel 4.10 Hasil Uji F

\begin{tabular}{lllllll}
\hline Model & & Sum of Squares & df & Mean Square & F & Sig. \\
\hline \multirow{3}{*}{1} & Regression & 614.455 & 2 & 307.227 & 48.458 & $.000^{\mathrm{b}}$ \\
& Residual & 614.985 & 97 & 6.340 & & \\
& Total & 1229.440 & 99 & & & \\
\hline
\end{tabular}

Sumber: Data Primer yang di olah SPSS 20, 2018

Uji simultan dibuktikan dengan suatu tingkat probabilitas 0,00 yang berada di bawah alpha 0,05 . Sementara, dengan menggunakan metode nilai $\mathrm{F}$ hitung $>\mathrm{F}$ tabel di ketahui bahwa F hitung sebesar 48.458 dan F tabel sebesar 3,09 dapat disimpukan bahwa F hitung lebih besar dari pada $\mathrm{F}$ tabel. Hal ini berarti bahwa secara bersama-sama variabel independen kualitas pelayanan dan fasilitas berpengaruh positif dan signifikan terhadap kepuasan pengguna.

Dengan demikian, dapat disimpulkan bahwa variabel kualitas pelayanan dan fasilitas memengaruhi kepuasan pengguna sehingga hipotesis H3 yang menyatakan "Kualitas Pelayanan dan Fasilitas berpengaruh Positif dan signifikan terhadap Kepuasan Pengguna perpustakaan di Politeknik Negeri Batam" diterima.

\section{Pembahasan Hasil Penelitian}

\section{Pengaruh kualitas pelayanan terhadap kepuasan pengguna}

Berdasarkan data output pengolahan sebelumnya data diambil dengan adanya pandangan positif variabel kualitas pelayanan terhadap kepuasan pengguna perpustakaaan di Politeknik Negeri Batam. Nilai sebesar 0,430 dan hasil output nilai signifikansi pada uji $\mathrm{t}$ sebesar $0,000<0,05$ dan $t_{\text {hitung }} 4.995>t_{\text {tabel }}$ 1.984. Berpengaruhnya antara kualitas pelayanan terhadap kepuasan pengguna perpustakaan di Politeknik Negeri Batam. Menurut (Tjiptono, $2008: 85$ ) tingkatan layanan yang diberikan sesuai dengan standart dan harapan pengguna perpustakaan itu sendiri biasanya sering disebut Kualitas pelayanan.Kualitas yang berpengaruh terhadap kepuasan pengguna jika semangkin baik kualitas suatu produk atau jasa maka akan semangkin puas seorang pengguna dan harapan nya juga semangkin merasa puas. Ini berkaitan juga dengan penelitan sebelumnya yang dilakukan (Sari, Purnama dan Jamil, 2016 : 1-15) yang menguji Pengaruh Kualitas Pelayanan Terhadap Kepuasan Anggota Perpustakaan Kota Medan. Kesimpulannya yaitu kualitas pelayanan berpengaruh positif dan kepuasan terhadap pengguna signifikan.

\section{Pengaruh Fasilitas terhadap kepuasan pengguna}

Berdasarkan hasil pengolahan data diperoleh bahwa adanya pengaruh positif dari variabel fasilitas terhadap kepuasan pengguna perpustakaan di Politeknik Negeri Batam. Besaran nilai 0,632 dan hasil output nilai yang memiliki signifikansi pada uji t sebesar $0,000<$ 0,05 dan nilai $t_{\text {hitung }} 8.561>t_{\text {tabel }} 3,09$. Berpengaruhnya diantara fasilitas dengan kepuasan pengguna perpustakaan di Politeknik Negeri Batam. Menurut (Hadiguna, 2008: 10) Fasilitas merupakan wadah yang berfungsi memfasilitasi kelancaran kegiatan perpustakaan. Semangkin bagus perlengkapan(fasilitas) yang disediakan kepada pengguna maka akan semakin meningkat suatu kepuasan pengguna. Hal ini sejalan dengan penelitian (Purwaningsih \& Ismiyati, 2016: 
456-657) yang menguji pengaruh fasilitas perpustakaan dan pelayanan perpustakaan terhadap minat baca di perpustakaan.yang mencanangkan bahwa fasilitas berpengaruh positif dan bersignifikan terhadap minat baca.

\section{Pengaruh Kualitas pelayanan dan Fasilitas terhadap kepuasan pengguna}

Penelitian ini memperoleh pengaruh kualitas pelayanan dan fasilitas secara simultan terhadap pengguna perpustakaan. Hasil pengujian dari uji $\mathrm{F}$ tersebut menyatakan jika dilihat dari keseluruhan secara bersama-sama maka kualitas pelyanan dan fasilitas berpengaruh positif serta bertaraf yang signifikan terhadap kepuasan pengguna. Dengan nilai $0,000<0,05$ dan nilai $\mathrm{F}_{\text {hitung }} 48.458>\mathrm{F}_{\text {tabel }} 3.09$

\section{SIMPULAN}

Kesimpulan dapat dilihat dari hasil suatu output penelitian dan suatu rangkuman penelitian yang sudah dijelaskan di penelitan sebelumnya, yaitu :

1. Terdapat suatu pengaruh antara kualitas pelayanan terhadap kepuasan pengguna perpustakaan di Politeknik Negeri Batam. Pengaruhnya Positif sebesar 0,430 dan hasil nilai signifikan pada uji t sebesar $0.000<0,05$ dan nilai t hing $4.995>\mathrm{t}$-tabel 1,984. Berpengaruhnya kualitas pelayanan dengan kepuasan pengguna perpustakaan di Politeknik Negeri Batam. Dari pengertian tersebut sejalan dengan penelitian dari (Sari, Purnama dan Jamil, 2016 : 1-15) yang menguji Pengaruh Kualitas Pelayanan Terhadap Kepuasan Anggota Perpustakaan Kota Medan. Yang memberi informasi bahwa kualitas pelayanan berpengaruh positif dan signifikan terhadap kepuasan pengguna.

2. Terdapat suatu pengaruh antara fasilitas terhadap kepuasan pengguna perpustakaan di Politeknik Negeri Batam. Pengaruhnya Positif sebesar 0,632 dan hasil nilai signifikan pada uji t sebesar $0.000<0,05$ dan nilai $\mathrm{t}$ hing $8.561>\mathrm{t}$-tabel 1,984 . Berpengaruhnya fasilitas dengan kepuasan pengguna perpustakaan di Politeknik Negeri Batam. Hal ini sejalan dengan penelitian (Purwaningsih \& Ismiyati, 2016: 456-657) yang menguji pengaruh fasilitas perpustakaan dan pelayanan perpustakaan terhadap minat baca di perpustakaan. Kesimpulan yang di berikan adalah fasilitas berpengaruh yang postitif dan memiliki signifikan terhadap minat baca.

3. Terdapat kualitas pelayanan dan fasilitas secara bersama-sama (simultan) terhadap kepuasan pengguna perpustakaan di Politeknik Negeri Batam. Out pengujian dalam uji F bisa dicerna bahwa secara bersama-sama kualitas pelayanan dan fasilitas terdapat pengaruh signifikan terhadap kepuasan pengguna, pernyataan ini bisa dilihat dengan nilai signifikansi sebesar 0,036 0,05 dan nilai $\mathrm{F}_{\text {hitung }} 48.485>\mathrm{F}_{\text {tabe }} 3,09$.

4. Hasil uji koefisien determinasi $\mathrm{R}^{2}$ yang didapat nilai sedimikian rupa ,500. Dalam hal Ini berarti persentase variabel X1 (kualitas pelayanan) X2 (fasilitas) dalam suatu model regresi sebesar 50\%. atau variabel $\mathrm{Y}$ (kepuasan pengguna) dapat dijelaskan oleh variabel X1 (Kualitas Pelayanan) X2 (Fasilitas) sebesar $50 \%$ sedangkan sisanya sebesar 50\% dapat dipengaruhi oleh variabel yang lain.

\section{DAFTAR PUSTAKA}

Abdurahman, M. (2009). Analisis Korelasi, Regresi, dan jalur dalam penelitian (edisi II, p. 30). Bandung: CV Pustaka Setia.

Adhitomo Wirawan, \& Risfandi. (2018). Pengaruh Fasilitas Perpustakaan, Kinerja Pustakawan dan Kualitas Informasi Terhadap Kepuasan Pengguna Mahasiswa dalam menggunakan Perpustakaan Politeknik Negeri Batam Adhitomo. Journal of Applied Business Administration, 2(1), 20-28.

Gaspers, V. (2008). Total Quality Management. jakarta: Pt Gramedia Pustaka Utama.

Hadiguna, R. ampuh. (2008). Tata Letak Pabrik. (ANDI, Ed.). Yogyakarta.

Hasan, A. (2013). Marketing dan Kasus-Kasus Pilihan. Yogyakarta: CAPS. 
Hilaliyah, S. A., Djawahir, A. H., \& Susilowati, C. (2017). Pengaruh Kualitas Layanan dan Kualitas Produk Kepuasan Pelanggan (Studi Pada Mahasiswa Pelanggan Kafe Ria Djenaka Malang) Sari Atul Hilaliyah, Achmad Helmy Djawahir, Christin Susilowati. Jurnal Bisnis Dan Manajemen, 4(2), 172-187.

Jogiyanto. (2008). Metodologi Penelitian. yogyakarta: ANDI OFFSET.

Kotler, P. (2009). Manajemen Pemasaran. Jakarta: Erlangga.

Kotler, P. \&, \& Keller, K. L. (2009a). Manajemen Pemasaran. (E. S. Y. Maulana,Adi;Hayati, Ed.) (edisi 13). Jakarta: Penerbit Erlangga.

Kotler, P., \& Keller, K. (2009b). Manajemen Pemasaran (13 Jilid 2). Jakarta.

Kurniasih, N. (2018). Analisis Pengaruh Pelayanan Perpustakaan Terhadap Kepuasan Pengguna Perpustakaan Di Institut Agama Islam Imam Ghozali. Jurnal Tawadhu, 2(1), 447-468. Retrieved from http://ejournal.iaiig.ac.id/index.php/TWD/article/viewFile/18/26

Laksana, F. (2008). Manajemen Pemasaran. yogyakarta: Graha Ilmu.

Majid, A. (2009). Perencanaan Pembelajaran. Bandung: PT Remaja Rosda Karya.

Martono, N. (2011). Metode Penelitian Kuantitatif , Analisis Isi dan Analisis Data Sekunder (Revisi-2). Jakarta: Rajawali Pers.

Misbahuddin dan Hasan, I. (2013). Analisis Data Penelitian dengan Statistik. (suryani, Ed.) (edisi 2). Jakarta: Bumi Aksara.

Moleong, J. lexy. (2011). Metodologi Penelitian Kualitatif (Edisi Revi). Bandung: PT Remaja RosdaKarya.

Mongkaren, S. (2013). Fasilitas dan kualitas pelayanan pengaruhnya terhadap kepuasan pengguna jasa Rumah Sakit Advent Manado. Emba, 1(4), 493-503.

Musfiqon, H. . (2012). Metodologi Penelitian Pendidikan. ( umi athelia Kurniati, Ed.). jakarta: PT Prestasi Pustakaraya.

Narbuko, C., \& Achmadi, A. (2016). Metodologi Penelian. (Bumi Aksara, Ed.). Jakarta.

Nasution, s. (2016). Metode Research. (Bumi Aksara, Ed.) (edisi 1). jakarta.

Nasuton, S. (2016). Metode Research. Jakarta: Bumi Aksara.

Nawawi, M. T., \& Puspitowati, I. (2015). Pengaruh Kualitas pelayanan dan fasilitas perpustakaan sebagai prediktor terhadap kepuasan civitas akademika Fakultas Ekonomi Universitas Tarumanagara di Jakarta, $X X(2), 320-334$.

Ningrum Roh, F. (2014). Pengaruh pelayanan perpustakaan terhadap kepuasan pengunjung di perpustakaan universitas muhammadiyah surakarta.

Priadana, H. M. sidik. (2009). Metodologi Penelitian Ekonomi dan Bisnis (edisi Pert). Yogyakarta: Graha Ilmu.

Priyatno, D. (2010). Paham Analisis Statistik Data dengan SPSS (Cetakan Pe). Jakarta: Media Kom.

Priyatno, D. (2012). Cara Kilat Belajar Analisis Data dengan SPSS 20. (B. Rini W, Ed.). yogyakarta: ANDI OFFSET.

Purwaningsih, D. C., \& Ismiyati. (2016). Pengaruh Fasilitas Perpustakaan dan Pelayanan Perpustakaan Terhadap Minat Baca di Perpustakaan., 5(2), 456-467.

Rangkuti, F. (2017). Custumer Care Excellence. (Mahardika, Ed.). Jakarta.

Risduwan. (2008). Penelitian. (Akdon, Ed.) (kelima). Bandung: ALFABET.

sangadji, etta mamang dan sopiah. (2010). Metodologi Penelitian. (oktaviani HS, Ed.). yogyakarta: ANDI.

Sangadji, M. dan S. (2013). Perilaku Konsumen. (ANDI, Ed.). yogyakarta.

Sanusi, anwar. (2011). Metodologi Penelitian Bisnis (cetakan ke). jakarta: Salemba Empat. 
Sari, Purnama dan Jamil, B. (2016). Pengaruh Kualitas Pelayanan Terhadap Kepuasan Anggota Perpustakaan Kota Medan. Jurnal Ilmu Administrasi Publik, 4(1), 1-15. Retrieved from http://ojs.uma.ac.id/index.php/publikauma

sugiyono. (2009). Metode penelitian Bisnis (cetakan ke). Bandung: Alfabeta.

Sugiyono. (2012a). Metode Penelitian Kuantitatif,Kualitatif,dan R\&G. Bandung: Alfabeta.

Sugiyono, dr. (2012b). Metode Penelitian Kuantitatif, Kualitatif, dan R\&D. Bandung: ALFABET,CV.

Tjiptono, F. (2008). Service Manajemen (Edisi Pert). yogyakarta: ANDI.

Tjiptono, F. (2012a). Service, Quality \& Satisfication Edisi 3. (ANDI, Ed.). Yogyakarta.

Tjiptono, F. (2012b). Strategi Bisnis Pemasaran. (andi, Ed.). yogyakarta.

Wantara, P. (2015). The Relationships among Service Quality, Customer Satisfaction, and Customer Loyalty in Library Services. International Journal of Economics and Financial, $5,264-269$.

Wibowoo, agung edy. (2012). Aplikasi Praktis SPSS dalam Penelitian. In Djojo Adji (Ed.)

(Cetakan 1). yogyakarta: PENERBIT GAVA MEDIA. 